\title{
Planar EBG Loaded UWB Monopole Antenna with Triple Notch Characteristics
}

\author{
Vamshi Kollipara, Samineni Peddakrishna*, Jayendra Kumar \\ School of Electronics Engineering, VIT-AP University, Amaravati, India \\ Received 14 July 2021; received in revised form 22 August 2021; accepted 23 August 2021 \\ DOI: https://doi.org/10.46604/ijeti.2021.8084
}

\begin{abstract}
A triple band-notched ultra-wideband (UWB) monopole antenna using a planar electromagnetic bandgap (EBG) design is proposed. The EBG unit cell composed by an Archimedean spiral and inter-digital capacitance demonstrates the notch frequencies. The antenna with EBG cells near the feed line occupies only $30 \times 36 \mathrm{~mm}^{2}$ with triple band-rejection characteristics. The three notched bands at $4.2 \mathrm{GHz}, 5.2 \mathrm{GHz}$, and $9.1 \mathrm{GHz}$ can be used in C-band satellite downlink, wireless local area network (WLAN), and X-band radio location for naval radar or military required applications. In addition, the proposed design is flexible to tune different notched bands by altering the EBG dimensions. The parametric analysis is studied in details after placing the EBG unit cells near the feed line to show the coupling effect. The input impedance and surface current distribution analysis are also analyzed to understand the effect of EBG at notch frequencies. The proposed design prototype is fabricated and characterized. A fairly considerable agreement is observed between simulated and measured results.
\end{abstract}

Keywords: triple notch, EBG, compact, WLAN, antenna

\section{Introduction}

In recent years, the unlicensed ultra-wideband (UWB) spectrum from $3.1 \mathrm{GHz}$ to $10.6 \mathrm{GHz}$ attracted a lot of interest for commercial use and was duly approved by the federal communications commission (FCC) in 2002 [1]. Wireless configurations were constantly being researched and used for a variety of applications such as remote sensing, radar detection, body-centric communication systems, wireless local area network (WLAN), and long term evolution (LTE) [2-4]. To realize such an application, UWB antennas are accomplished as one of the promising challenges for UWB communication systems due to their simple configuration, low cost, and small size [5]. Recently, UWB frequency selective surface (FSS) has been proposed for stopband shielding applications [6]. However, preventing interference from certain existing narrow-band spectra including location tracking applications for emergency services (LAES), WLAN, LTE, mobile broadcasting, radio-allocation within the UWB range using simple configuration and compact size is a major challenge for these systems. Numerous effective and possible solutions have been reported to this overlapping problem by designing UWB antennas with band-rejection characteristics. A state of art review of UWB rejection topologies has been reported and described in the literature with diverse radiating components such as elliptical/circular, rectangular, and hexagonal shapes [7] by either using microstrip feed or coplanar waveguide (CPW) feed method.

The commonly used methods are embedding slots on the radiating surface/in the ground plane [8-10] or adding a parasitic element near the radiating element or on the other side of the substrate [11-14]. Single and dual/multiple rejection bands can be realized by inserting either slots/slits such as reversed pi shape slot [8], split rectangle ring and open-ended slot [9-10], and Archimedean spiral-shaped slot [11] or parasitic resonators such as vertical strip [12-13] and reverse U strip [14]. To attain an additional notch, another slot/slit is incorporated with different dimensions. However, these designs are not conquered to produce more than two band-notched characteristics due to strong mutual coupling between the notched elements. Other

* Corresponding author. E-mail address: krishna.samineni@gmail.com 
techniques also have been proposed to achieve multi notches with stacked multilayer [15], but the increase in the structural complexity and fabrication cost are major disadvantages. To improve the shortfalls such as mutual coupling interference on the notched elements as well as reducing structural complexity along with independent control of different notched bands, electromagnetic bandgap (EBG) structures have been introduced in the notched UWB antenna designs. EBG structures can be used as a band stop filter (BSF) to obtain notches in UWB antenna designs without effecting antenna behavior.

In literature, various types of EBG unit cells have been designed and used for realizing single, dual, and multi-notch characteristics in UWB design. Yazdi et al. [16] and Jaglan et al. [17] have realized only one notched band using EBG with uniform dimensions of EBG cells, whereas Peng et al. [18], Alshamaileh et al. [19], and Jaglan et al. [20-22] have realized dual/multi-notched bands using multi-dimensional EBG structures. Li et al. [23] have proposed a pair of the slotted patch and edge-located via mushroom-type EBG with uniform dimensions to obtain dual notched bands. However, the quadrature dimension of the EBG structure occupies more surface area in the design. Moreover, the presence of ground connecting via from patch in the mushroom EBG structures increases the design complexity [16-22]. To eliminate the problem with ground connecting via into the substrate, recently uni-planar EBG structures without ground connecting via have been proposed for band-notched characteristics [24-26]. However, these structures also failed to produce more than one notch characteristic per EBG unit cell.

In this study, the authors design a triple band-notched UWB monopole antenna together by proposing a uni-planar EBG to produce dual band-notched characteristics. The EBG cells coupled with the microstrip feed line provide dual narrow bandgaps, which are used in obtaining notches in the UWB antenna. The proposed EBG unit cells are creating dual notched bands with uniform cell dimensions, compact, and eliminate ground connecting via design complexity. In addition, the notched band flexibility is due to a change in dimensions of the EBG unit cell [27]. Moreover, the overall dimensions of the proposed triple band-notched design occupy, only a size of $30 \times 36 \mathrm{~mm}^{2}$ surface area including EBG unit cells. In the proposed design, a pair of Archimedean spirals with interdigital capacitance EBG unit cells with different dimensions is utilized to obtain notched characteristics at $4.2 \mathrm{GHz}, 5.2 \mathrm{GHz}$, and $9.1 \mathrm{GHz}$. Finally, the prototype of the optimized triple band-notched UWB antenna is fabricated and characterized.

\section{Antenna Configuration and Description}

Fig. 1 shows a proposed triple notched operation compact monopole UWB antenna using microstrip feed. The antenna geometry is designed using RT duroid substrate $\left(\varepsilon_{r}=2.2\right.$, thickness $=0.762 \mathrm{~mm}$, and $\left.\tan \delta=0.0009\right)$ of surface area $W \times L=30$ $\times 36 \mathrm{~mm}^{2}$ by CST Microwave studio. It consists of a rectangular radiating element and a pair of Archimedean spiral EBG surfaces on one side of the substrate sheet with a partial ground plane on the other side. In addition, the radiating element consists of two horizontal truncated stepped rectangular slots on the bottom edge of the patch. These slots are used to realize an acceptable impedance bandwidth within the UWB region. The pair of two different EBG cells with a periodic dimension of $P_{1}$ $=5.2 \mathrm{~mm}$ and $P_{2}=4.4 \mathrm{~mm}$ is placed near the feed line to produce three notch frequencies. All the dimensions shown in Fig. 1 are presented in Table 1.

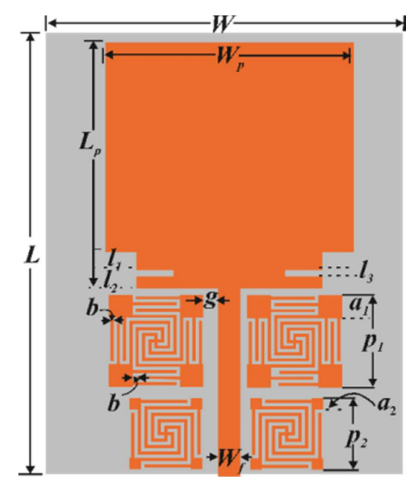

(a) Top view

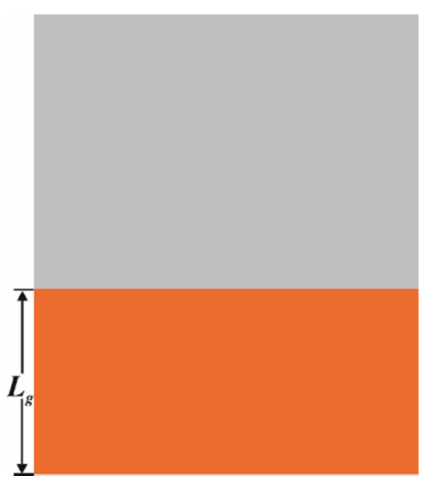

(b) Bottom view

Fig. 1 The proposed triple notched antenna 
Table 1 The proposed antenna dimensional parameters

\begin{tabular}{|c|c|}
\hline Parameters & Dimension $(\mathrm{mm})$ \\
\hline Substrate length $(L)$ & 36 \\
\hline Substrate width $(W)$ & 30 \\
\hline Patch length $\left(L_{p}\right)$ & 20 \\
\hline Patch width $\left(W_{p}\right)$ & 18 \\
\hline Ground length $\left(L_{g}\right)$ & 14.5 \\
\hline Slot length $1\left(l_{1}\right)$ & 1.5 \\
\hline Slot length $2\left(l_{2}\right)$ & 1.5 \\
\hline Slot length $3\left(l_{3}\right)$ & 0.5 \\
\hline Feed width $\left(W_{f}\right)$ & 1.8 \\
\hline EBG cell period $\left(P_{1}\right)$ & 5.2 \\
\hline EBG cell period $\left(P_{2}\right)$ & 4.4 \\
\hline EBG cell corner patch width $\left(a_{1}\right)$ & 1.1 \\
\hline EBG cell corner patch width $\left(a_{2}\right)$ & 0.7 \\
\hline EBG cell strip width $(b)$ & 0.2 \\
\hline EBG cell and feed gap $(g)$ & 0.1 \\
\hline EBG cell gap $\left(g_{1}\right)$ & 0.15 \\
\hline Substrate thickness & 0.762 \\
\hline
\end{tabular}

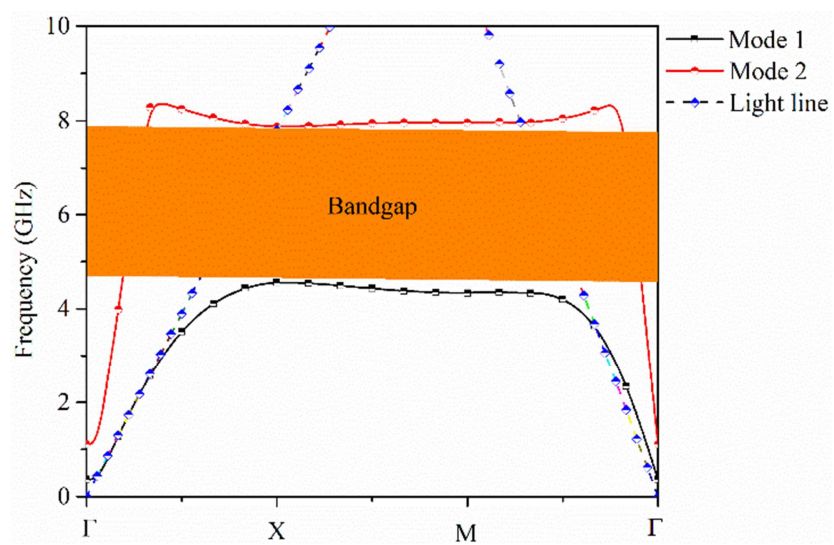

Fig. 2 Dispersion bandgap properties of the proposed EBG [28]

In the proposed design [28], the EBG cell consists of symmetrical square metal patches at four corners and two narrow interdigital capacitance lines between the corner patches. The corner patches and interdigital capacitance lines introduce the capacitance. From the corner patches, narrow spiral strip lines are extended to the center of the unit cell to introduce the inductance. Thus, a periodic LC network is realized from the capacitance " $C$ " and inductance " $\mathrm{L}$ " resulting from the frequency bandgap. The center frequency of the bandgap is determined by $\omega_{0}=1 / \sqrt{\mathrm{LCC}}$, and the relative bandwidth $\Delta \omega / \omega_{0}$ is directly proportional to L/C. To further understand the bandgap property of the design, dispersion properties are extracted by simulating a single unit cell with periodic boundary conditions in the eigenmode solver. The eigenmode solver determines the resonance frequency for a given wavenumber which is an important parameter to describe the propagation property of electromagnetic waves. The simulated dispersion diagram for the proposed EBG unit cells is illustrated in Fig. 2. In this diagram, the horizontal axis shows the wavenumber, and the vertical axis represents the frequency. The corresponding bandgap 4.5-7.9 GHz with a bandwidth of $3.4 \mathrm{GHz}$ is observed.

To understand the notched behavior of the EBG cells introduced in the design, a very common method such as the dual-port microstrip feed line method as shown in Fig. 3(a) is employed. To understand the characteristics of the EBG structure, there are three different methods, i.e., the reflection phase, the transmission microstrip line, and the dispersion diagram. Moreover, to investigate the bandgap characteristics, the reflection phase and the transmission line are sufficient. The surface wave bandgap of the EBG structure transmission response can be easily identified in contrast with dispersion diagram which requires higher time and memory allocation [29]. Using this method, the simulated reflection coefficient and vector current 
distribution analysis are performed to a pair of EBG unit cells. The reflection coefficient shown in Fig. 3(b) over a frequency concerning Case \#1 and Case \#2 is represented corresponding to EBG cells dimensions $P_{1}=5.2 \mathrm{~mm}$ and $P_{2}=4.4 \mathrm{~mm}$, respectively. It is observed from Fig. 3(b) that the EBG unit cell in Case \#1 resonates at 4.2 GHz, 9.1 GHz, whereas in Case \#2 it resonates at $5.2 \mathrm{GHz}$ and $9.2 \mathrm{GHz}$. From this, it can be noticed that each pair of unit cells are capable of producing two different notches in the proposed design. However, from the proposed dimensions, the second notch produced by both cells is coinciding with a small deviation. Thus, the proposed antenna is considered only for the triple-notched band.

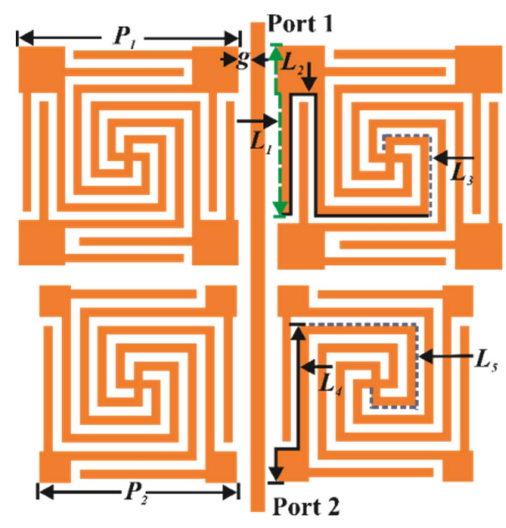

(a) Microstrip line method

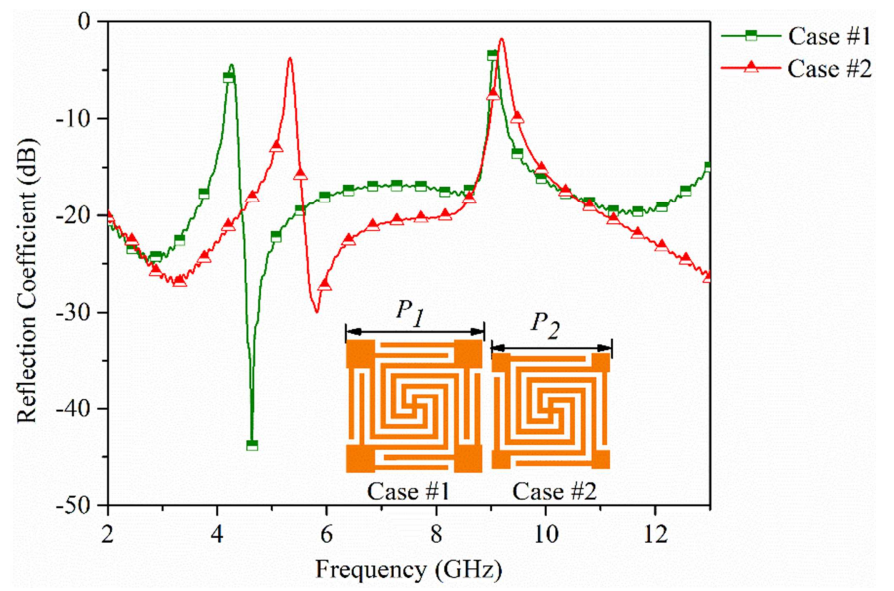

(b) Effect of EBG near the feed line

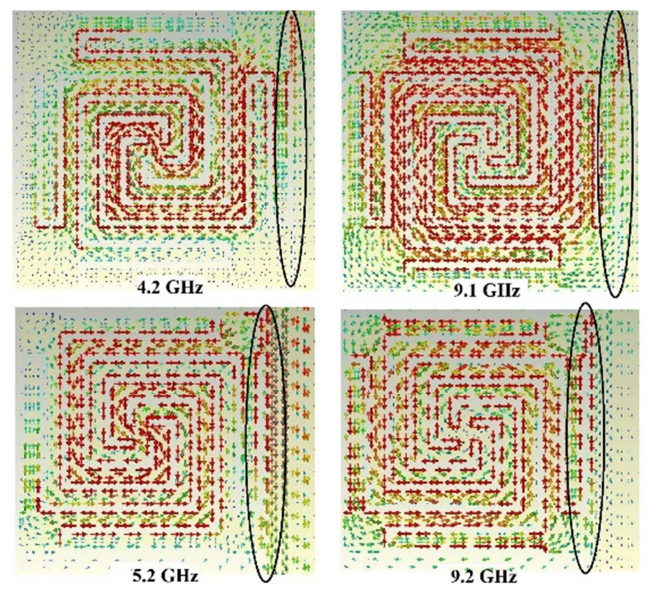

(c) Surface current

Fig. 3 Notched characteristics of EBG using microstrip line-based approach

Furthermore, to control the band frequencies, the EBG dimensions are to be modified. As the dimensions of the EBG unit cell change, the spiral inductance and interdigital capacitance also change. This causes a change in the frequency band so that the notched band as per the dimensions can be controlled [28]. To further confirm the notched behavior, the vector current distribution at their corresponding notch frequencies of EBG unit cells in Case \#1 and Case \#2 is illustrated in Fig. 3(c). It is observed that the direction of current flow to the edge of the feed line opposes the current flow in the EBG, which confirms the stopband resonance. This has been highlighted by representing circles in Fig. 3(c). Moreover, the majority of the current concentrated in the center of the EBG suggests a significant effect on the antenna performance for band rejection. In addition, from the direction of vector current distribution on EBG, the resonance wavelengths $\lambda_{1}$ at $4.2 \mathrm{GHz}$ in Case \#1, $\lambda_{2}$ at $9.1 \mathrm{GHz}$ in Case \#1, $\lambda_{3}$ at $5.2 \mathrm{GHz}$ in Case \#2, and $\lambda_{4}$ at $9.2 \mathrm{GHz}$ in Case \#2 are calculated using Eqs. (1), (2), (3), and (4), respectively.

$$
\begin{aligned}
& \lambda_{1}=\frac{c}{f_{1} \sqrt{\varepsilon_{r}}}=4 \times\left(L_{2}+L_{3}\right) \\
& \lambda_{2}=\frac{c}{f_{2} \sqrt{\varepsilon_{r}}}=4 \times\left(L_{1}+L_{2}-L_{3}\right)
\end{aligned}
$$




$$
\begin{aligned}
& \lambda_{3}=\frac{c}{f_{3} \sqrt{\varepsilon_{r}}}=4 \times\left(L_{4}+L_{5}\right) \\
& \lambda_{4}=\frac{c}{f_{4} \sqrt{\varepsilon_{r}}}=4 \times\left(L_{5}-L_{4}\right)
\end{aligned}
$$

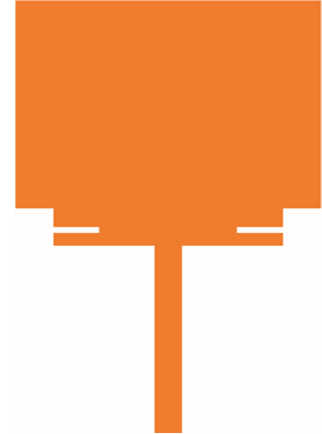

(a) Antenna \#1

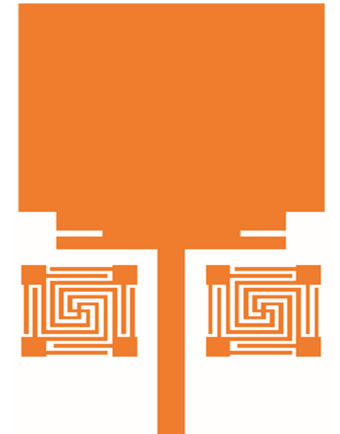

(b) Antenna \#2

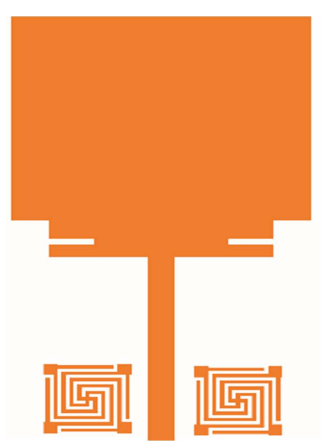

(c) Antenna \#3

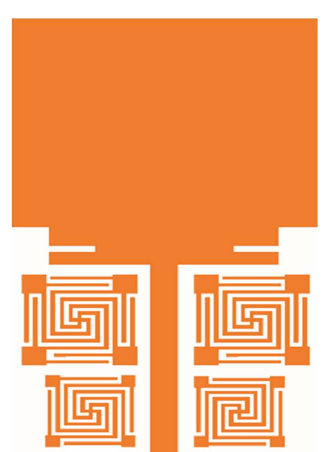

(d) Antenna \#4

Fig. 4 Design procedure for achieving multi band-notched antennas

Furthermore, to investigate the effect of EBG unit cells on UWB antenna, a stepwise design procedure shown in Fig. 4 is considered. Here, Antenna \#1 is basically a UWB antenna, which can have impedance matching over the complete UWB region, whereas Antenna \#4 is a triple band-notched UWB antenna. In between, Antenna \#2 and Antenna \#3 are two independent dual band-notched UWB antennas corresponding to EBG unit cells with periodic dimensions $P_{1}=5.2 \mathrm{~mm}$ and $P_{2}$ $=4.4 \mathrm{~mm}$, respectively. The analysis of all these designs is discussed in the following section.

\section{Results and Discussion}

\subsection{Full UWB design}

The realization of the UWB monopole antenna (Antenna \#1), with $S_{11}$ curves, is presented in Fig. 5. It is plotted with different cases, i.e., without horizontal truncated slot (Case \#1), with step-like design (Case \#2), and with horizontal truncated slots (Case \#3) on the bottom edge of the radiating element. Here, it is observed that there is no impedance UWB bandwidth $\left(\mathrm{S}_{11}<-10 \mathrm{~dB}\right)$ with Case \#1. By modifying the design from Case \#1 to Case \#2, the matching is extended to around $8 \mathrm{GHz}$. To further increase the matching bandwidth, the design is further modified to Case \#3, which produces a matching bandwidth beyond $12 \mathrm{GHz}$ from $3 \mathrm{GHz}$.

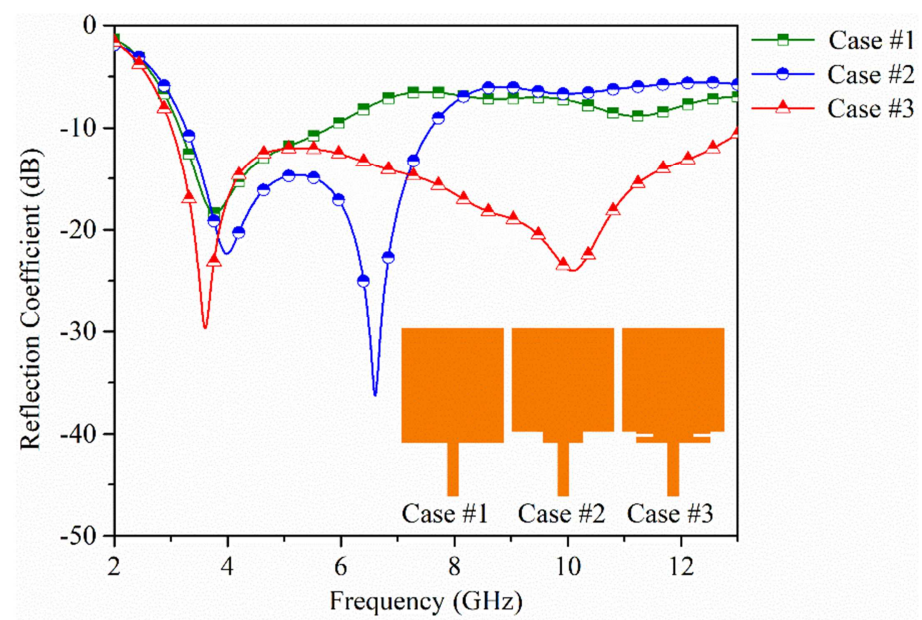

Fig. 5 Design steps to achieve impedance matching for Antenna \#1 


\subsection{Double notched design}

To avoid interference within the UWB range, it is proposed to incorporate a pair of EBG unit cells with different dimensions. These unit cells are independently coupled to the feed line to form Antenna \#2 and Antenna \#3 (Fig. 4). To study the notch performance of these antennas, the parametric analysis of Antenna \#2 and Antenna \#3 is performed. Here, the parametric analysis of Antenna \#2 and Antenna \#3 is performed concerning the gap $(g)$ from $0.1 \mathrm{~mm}$ to $0.25 \mathrm{~mm}$ between the EBG unit cell and the feed line. As can be seen from the parametric analysis depicted in Fig. 6, as the parameter " $g$ " increases, the lower frequency of the notched level decreases in both Antenna \#2 and Antenna \#3 because of the reduction in the coupling. The upper-frequency notch is negligibly affected because of the strong coupling between the unit cell and the ground plane. It is observed that for $P_{1}=5.2 \mathrm{~mm}$ unit cell, the notch level is $-1 \mathrm{~dB}$ and $-2.8 \mathrm{~dB}$ at $9.1 \mathrm{GHz}$ with respect to $g=0.1 \mathrm{~mm}$ and $g=0.25 \mathrm{~mm}$ respectively, whereas at $4.2 \mathrm{GHz}$ with similar EBG cell dimensions the notch level is observed as $-3 \mathrm{~dB}$ and $-8 \mathrm{~dB}$ with respect to $g=0.1 \mathrm{~mm}$ and $g=0.25 \mathrm{~mm}$ respectively. Also, for $P_{1}=4.4 \mathrm{~mm}$, similar kind of variation is noted at $5.2 \mathrm{GHz}$ and $9.2 \mathrm{GHz}$ notch frequencies.

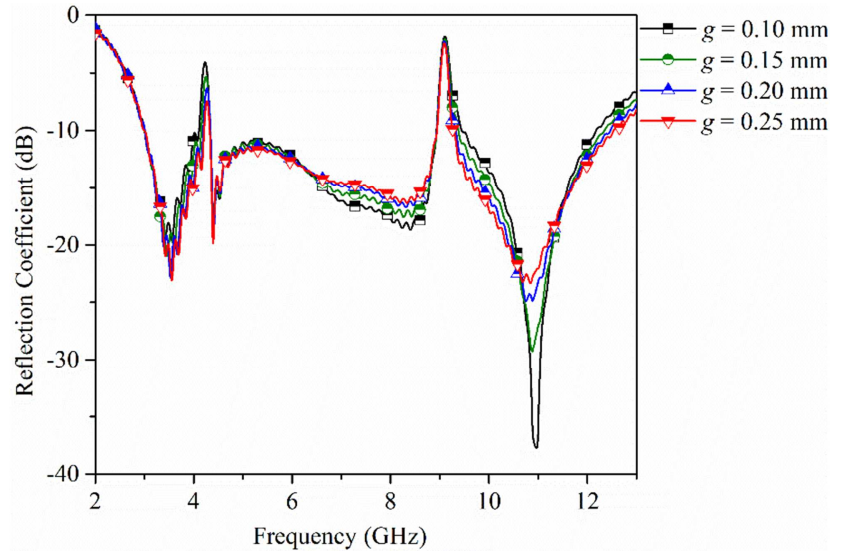

(a) Antenna \#2

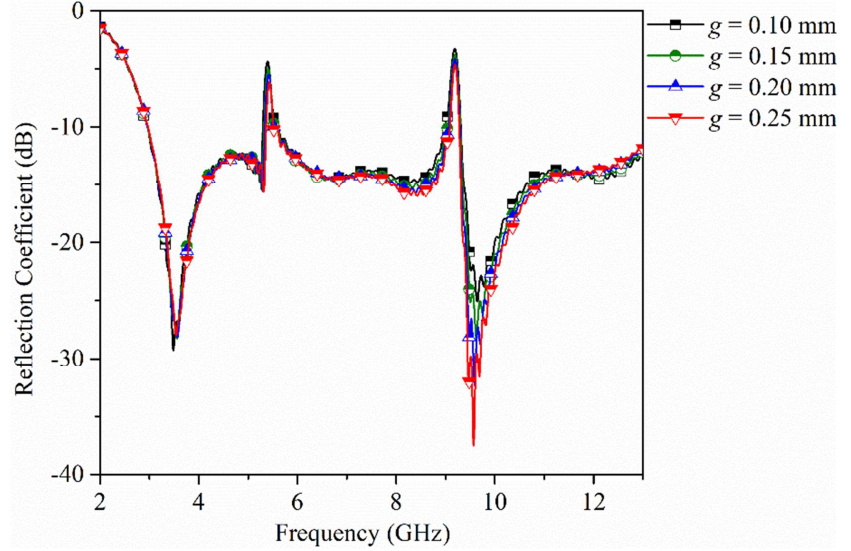

(b) Antenna \#3

Fig. 6 EBG parametric variation of the gap $(g)$ coupled to the feed line

\subsection{Triple notched design}

To validate the combined result of the two EBG unit cells, Antenna \#4 is formed and parametric analysis is performed between the EBG unit cell gap $\left(g_{1}\right)$. The parametric variation of Antenna \#4 concerning $g_{1}$ is shown in Fig. 7. It is quite apparent from the results that as the distances between the EBG unit cells are varied, the notched level is slightly affected. This indicates that the coupling effect between EBG cells is negligibly small. It is further observed that the notched behavior of the proposed antenna only attains three notched characteristics. This is because of uniform notch behavior and the combined effect of both the EBG unit cells at around the $9.1 \mathrm{GHz}$ band region. Also, quite wider notch bandwidth is observed due to the combined effect of individual notches.

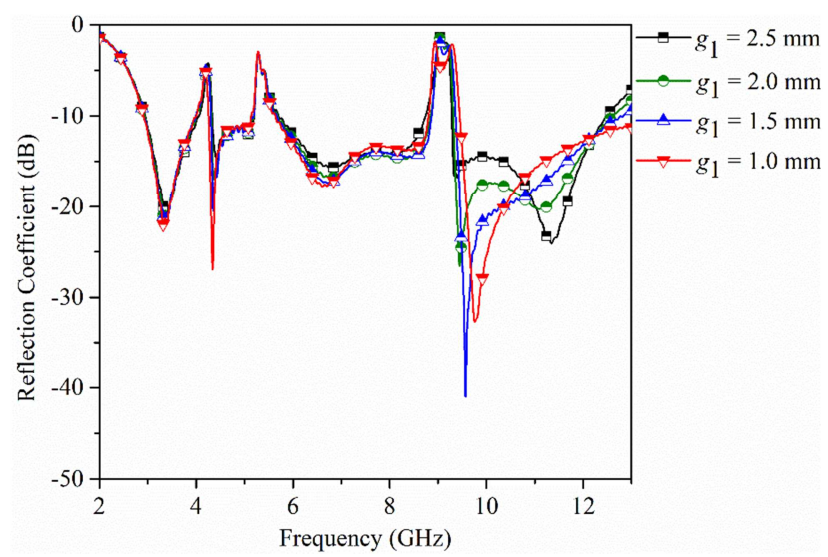

Fig. 7 Study of the coupling effect between two EBGs of Antenna \#4 
Furthermore, based on the parametric analysis, the optimized reflection curves of four designed antennas from Antenna $\# 1$ to Antenna \#4 are depicted in Fig. 8. As observed from the results, the reflection coefficient of Antenna \#1 has an impedance matching below $-10 \mathrm{~dB}\left(\mathrm{~S}_{11}<-10 \mathrm{~dB}\right)$ over an operating range beyond $12 \mathrm{GHz}$ from $3 \mathrm{GHz}$ without any notches; while Antenna \#2 and Antenna \#3 produce two independent notch frequencies due to EBG unit cells near the feed line with the gap $g=0.15 \mathrm{~mm}$. The notched frequencies of these antennas are observed at $4.2 \mathrm{GHz}$ and $9.1 \mathrm{GHz}$ corresponding to Antenna \#2 and 5.2 GHz and 9.2 GHz corresponding to Antenna \#3, respectively. Finally, the combined effect of EBG unit cells on Antenna \#4 is observed with three different notched frequencies at 4.2 GHz (3.9-4.3 GHz), 5.2 GHz (5.1-5.7 GHz), and 9.1 $\mathrm{GHz}(8.7-9.3 \mathrm{GHz})$.

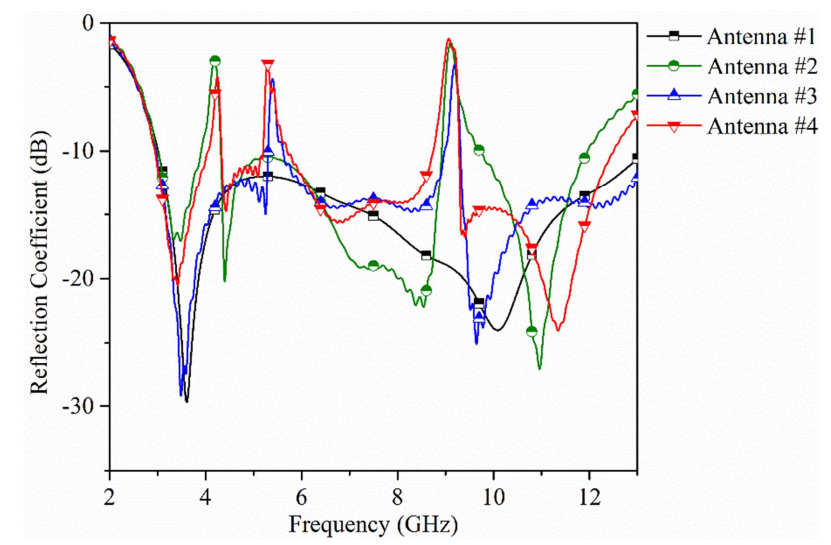

Fig. 8 Reflection coefficient comparison of Antenna \#1 to Antenna \#4

\subsection{Impedance and surface current analysis}

The investigation on impedance variation over a designated frequency band is studied due to the presence of EBG for the occurrence of notched characteristics. The variation of the real and imaginary impedance of Antenna \#4 is plotted in Fig. 9. As observed from the real impedance, it varies around $50 \Omega$ except at the notched frequencies, whereas the imaginary impedance varies around $0 \Omega$ throughout the UWB frequency range except at the notched frequency range. The sudden variation of real and imaginary impedance values is because of high energy reflection to the input port which causes impedance mismatch.

Besides impedance, the current distribution at notch $(4.2 \mathrm{GHz}, 5.2 \mathrm{GHz}$, and $9.1 \mathrm{GHz})$ frequency and resonance (3.5 GHz, 6.5 GHz, and 10.2 GHz) frequency shown in Fig. 10 indicates that more current density and less current density is concentrated within EBG at the notch and resonance frequencies. In addition, the high current densities surrounding EBG at the notched frequency cause near-field radiation to be counteracted, resulting in high energy being reflected towards the input port and band-notched features being achieved. Furthermore, except for triple band-notches, the surface current is distributed uniformly throughout the antenna across the specified frequency band. The current distributions surrounding EBG are very low for frequencies other than the notch frequencies.

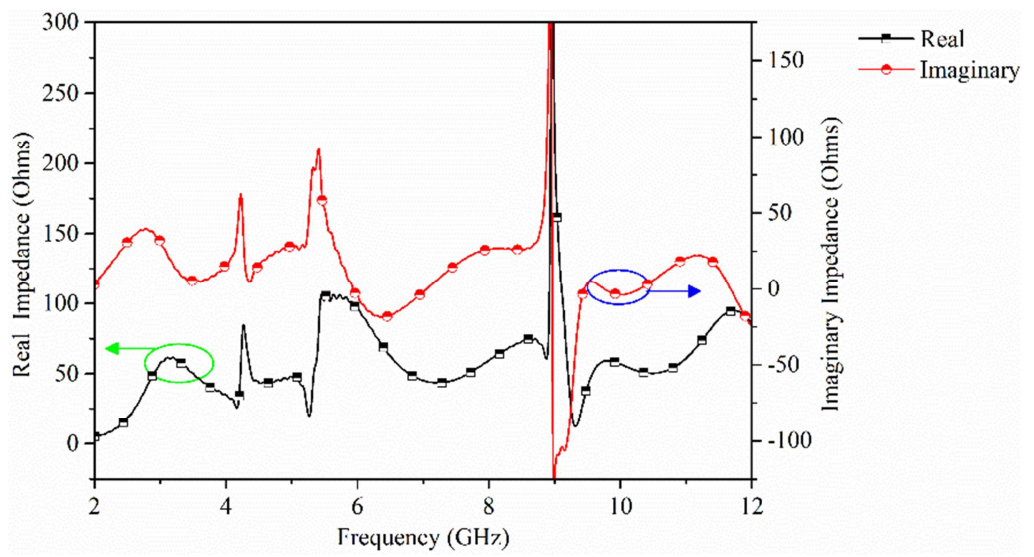

Fig. 9 Input impedance variation of Antenna \#4 


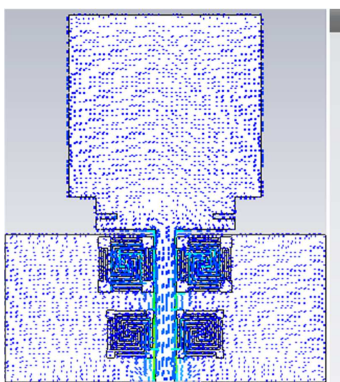

(a) $3.5 \mathrm{GHz}$

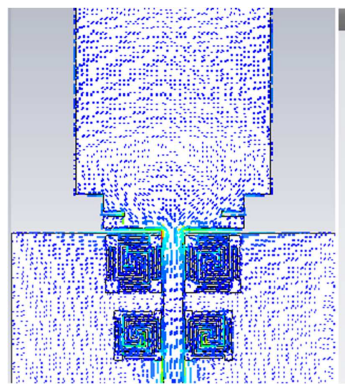

(d) $6.5 \mathrm{GHz}$
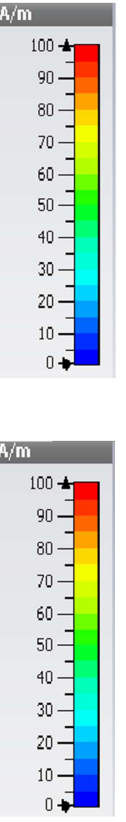

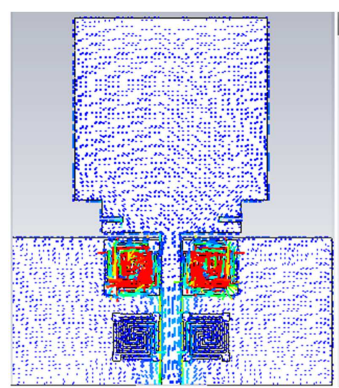

(b) $4.2 \mathrm{GHz}$

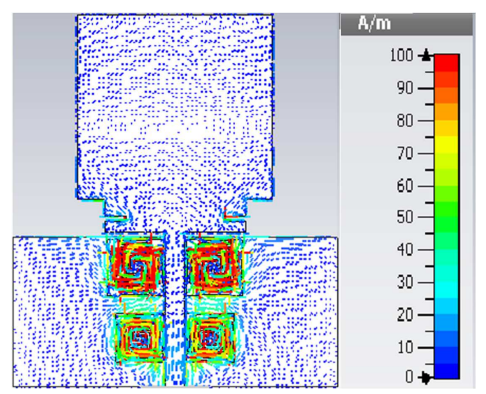

(e) $9.1 \mathrm{GHz}$

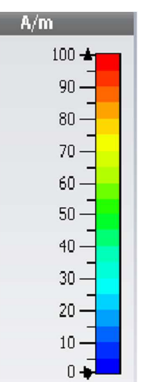

Fig. 10 Surface current distribution of Antenna \#4

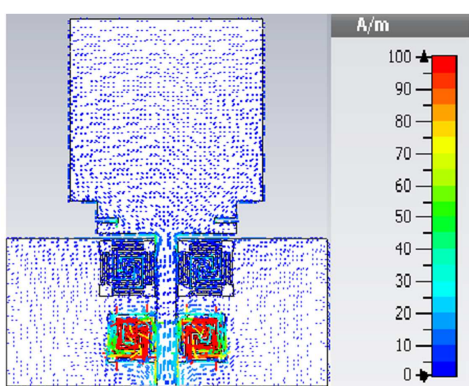

(c) $5.2 \mathrm{GHz}$

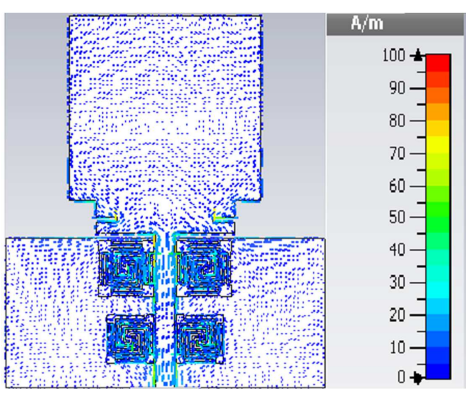

(f) $10.2 \mathrm{GHz}$

\subsection{Group delay}

The investigation of distortion in the UWB antenna can be carried out by using group delay. To get a desirable UWB frequency range, it requires a stable group delay with less non-uniformity. To understand the time domain analysis, i.e., group delay of the proposed antenna, two identical antennas are placed in such a way that the transmitting and receiving are opposite each other and separated with a far-field distance of $30 \mathrm{~cm}$. As observed from Fig. 11, the group delay is relatively stable/uniform (i.e., < 1) except for the three notch bands. The uniform group delay makes the proposed antenna is suitable for various useful applications.

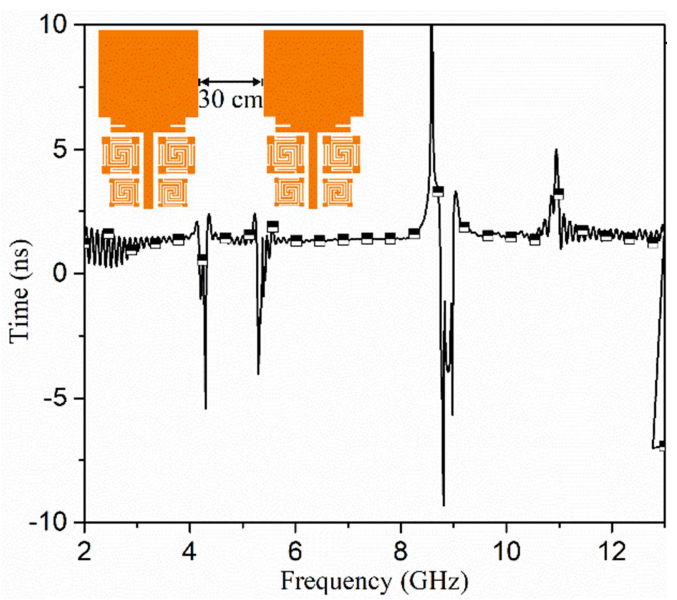

Fig. 11 Group delay for triple band-notched UWB antenna system

\section{Experimental Validation}

A prototype of Antenna \#4 is fabricated and measured (Fig. 12) for validation purposes. The pattern of antenna \#4 is measured using the amitech radiation pattern measurement setup. A high gain ( $13 \mathrm{dBi})$ horn antenna is used as a source and the antenna under test (AUT) is placed in the far-field. AUT is installed on an automated rotator equipped with the data logger. The experiment is performed in an electromagnetically shielded chamber. Later, the obtained pattern is normalized and presented.

Vector network analyzer (VNA) is used for $\mathrm{S}_{11}$ characterization. 


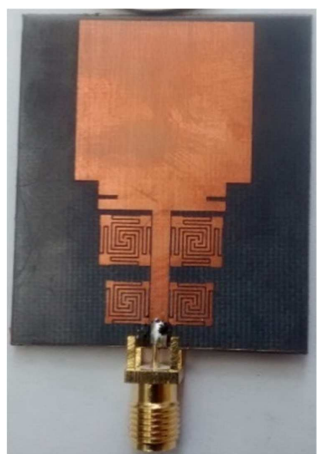

(a) Top layer

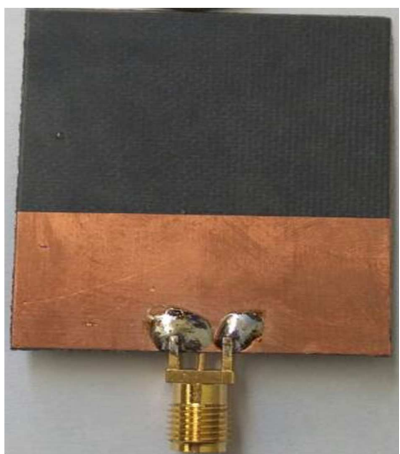

(b) Bottom layer

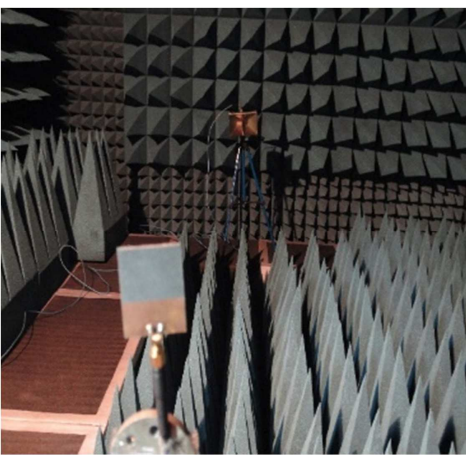

(c) Measurement setup

Fig. 12 Fabricated prototype and measurement setup

Fig. 13 shows the comparison of the simulated and measured reflection coefficient and the realized peak gain of Antenna \#4. The reflection coefficient comparison indicates a very close agreement between simulation and measurement with a negligibly small deviation. This deviation may be due to fabrication tolerances, calibration of VNA, etc. Also, the gain of the antenna is measured using the 2-antenna method with two identical antenna gain connected to two ports of VNA, and $\mathrm{S}_{21}$ reading is noted. Later, one of these antennas is replaced by AUT and compared with earlier observations to find the gain of AUT. The realized gain clearly indicates a significant gain reduction at $4.2 \mathrm{GHz}, 5.2 \mathrm{GHz}$, and $9.1 \mathrm{GHz}$ notch frequency bands.

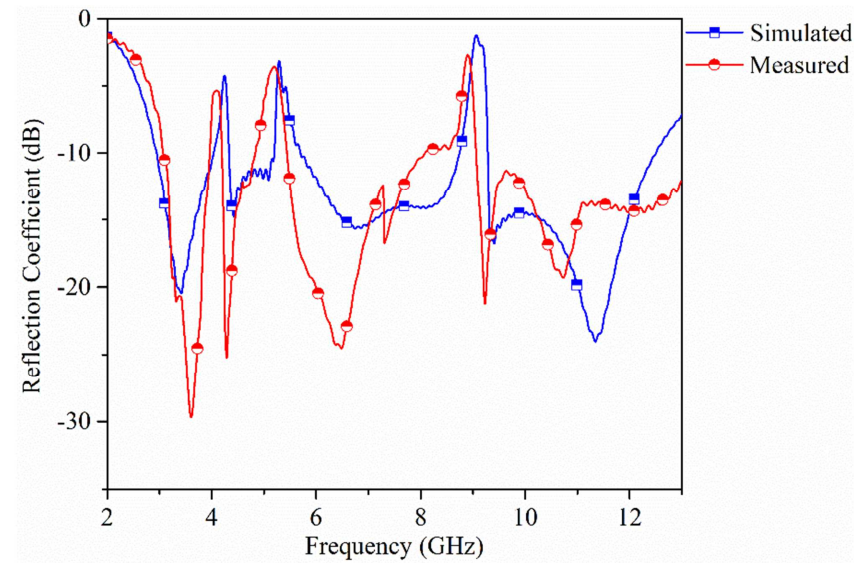

(a) Reflection coefficient comparison

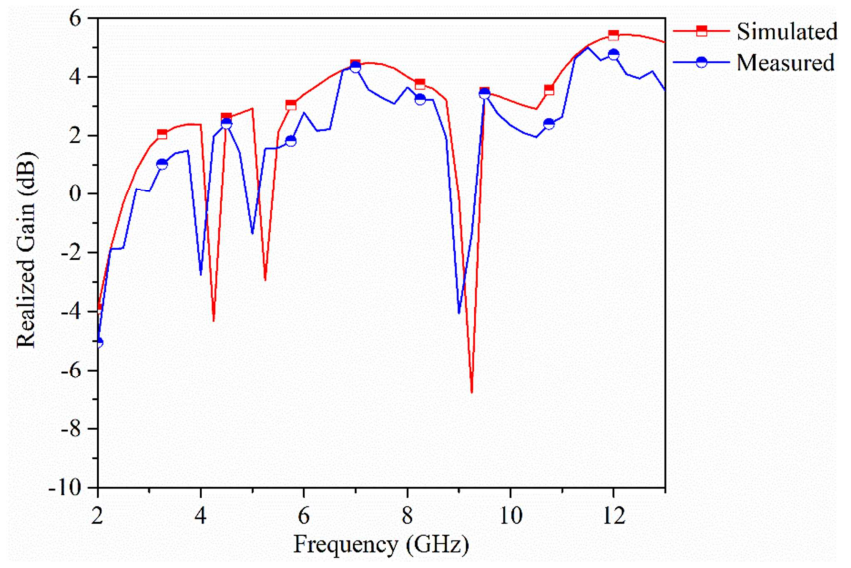

(b) Gain variation comparison

Fig. 13 Reflection coefficient and realized peak gain comparison of Antenna \# 4

Furthermore, the simulated and measured radiation patterns are compared in Fig. 14. Here, the chosen pattern frequencies are considered as working bands of the antenna $\left(S_{11}<-10 \mathrm{~dB}\right)$ in the UWB region. As observed in Fig 14, the antenna is providing a desired omnidirectional dipole-like pattern in H- and E-plane, respectively. There is a slight deviation from omni and dipole-like pattern $10.0 \mathrm{GHz}$, i.e., at a higher frequency. This is because of the loss due to cross-polarization. Further, the comparison of the proposed structure with existing literature is presented in Table 2.

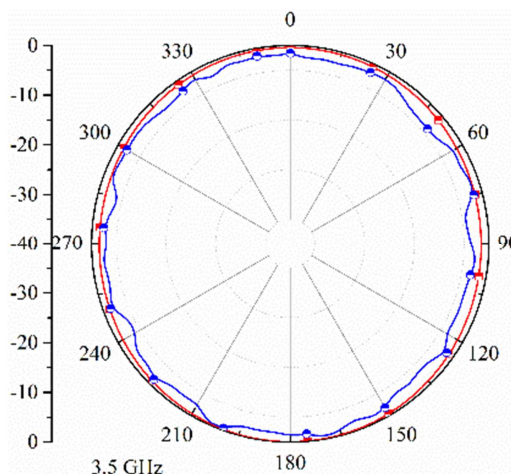

$3.5 \mathrm{GIIz}$

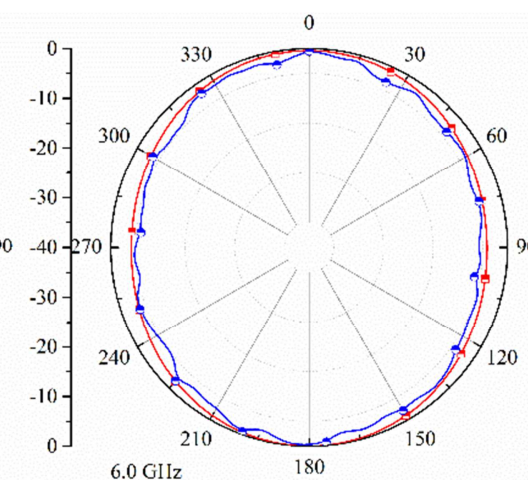

(a) H-plane

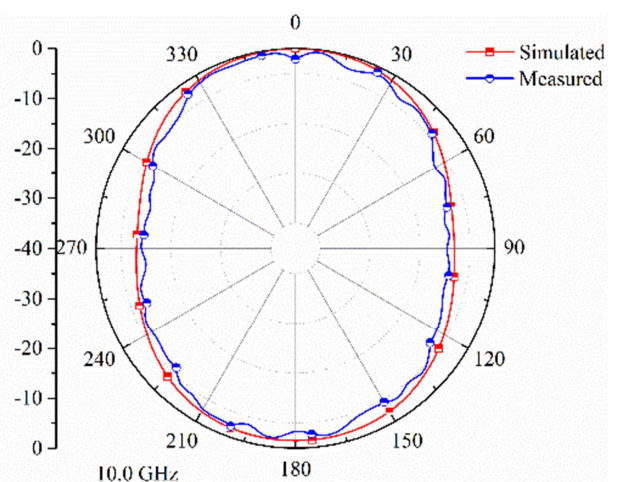

$10.0 \mathrm{GH}$

Fig. 14 Radiation pattern comparison 

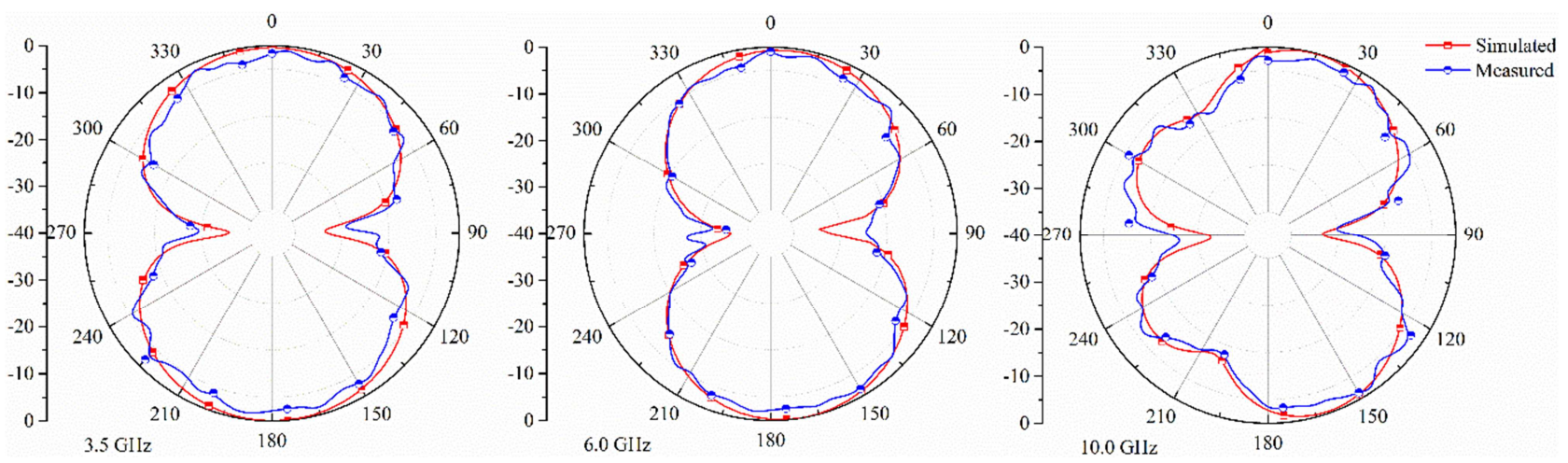

(b) E-plane

Fig. 14 Radiation pattern comparison (continued)

Table 2 Comparison of the proposed antenna with reported literature

\begin{tabular}{|c|c|c|c|}
\hline Ref. & $\begin{array}{c}\text { Dimensions } \\
(W \times L \times H) \text { in } \mathrm{mm}\end{array}$ & Notch frequency bands $(\mathrm{GHz})$ & Number of notch bands \\
\hline$[18]$ & $38 \times 40 \times 1$ & $5.3-5.8$ & Single \\
\hline$[19]$ & $66.3 \times 66.3 \times 0.8$ & $3.6-3.9$ and 5.6-5.8 & Dual \\
\hline$[20]$ & $58 \times 45 \times 1.6$ & $3.3-3.6$ and 5-6 & Dual \\
\hline$[21]$ & $42 \times 50 \times 1.6$ & $3.3-3.6$ and 5-6 & Dual \\
\hline$[22]$ & $42 \times 50 \times 1.6$ & $3.3-3.8,5.15-5.825$, and 7.1-7.9 & Triple \\
\hline$[23]$ & $24 \times 28 \times 1$ & $3.3-3.7,5.14-5.46$, and 5.6-5.9 & Dual \\
\hline$[24]$ & $42 \times 50 \times 1.6$ & $6.05-7.43$ and $6.23-7.68$ & Dual \\
\hline$[25]$ & $40 \times 52 \times 0.762$ & $3.3-3.7$ and $6.5-7.2$ & Triple \\
\hline$[26]$ & $31.3 \times 34.9 \times 1.6$ & $2.53-3.15,3.23-3.68$, and 3.92-4.30 & Triple \\
\hline
\end{tabular}

\section{Conclusions}

In this study, a compact triple band-notched UWB antenna by using uni-planar EBG structures is proposed and discussed. The triple notched bands are obtained by a pair of symmetrically coupled EBG unit cells to the antenna feed line with a gap ( $g$ ) of $0.15 \mathrm{~mm}$. The proposed antenna exhibits a broad impedance bandwidth from 3 to $13 \mathrm{GHz}$ with notched frequencies at 4.2 GHz LAES, 5.2 GHz WLAN, and 9.1 GHz radio allocation bands. In addition, the antenna offers independent control of notch frequency with incremental dimensions. The measured results show that the proposed antenna achieves a UWB impedance bandwidth $\left(\mathrm{S}_{11}<-10 \mathrm{~dB}\right)$ with triple band-notched characteristics successfully. As per the measured results, this compact monopole antenna could be an appropriate candidate for communication systems.

\section{Conflicts of Interest}

The authors declare no conflict of interest.

\section{References}

[1] Federal Communications Commission Revision of Part 15 of the Commission's Rules Regarding Ultra-Wideband Transmission Systems, FCC 02-48, 2002.

[2] I. Y. Immoreev, "Practical Applications of UWB Technology," IEEE Aerospace and Electronic Systems Magazine, vol. 25, no. 2, pp. 36-42, February 2010.

[3] R. S. Uqaili, J. A. Uqaili, S. Zahra, F. B. Soomro, and A. Akbar, "A Study on Dual-Band Microstrip Rectangular Patch Antenna for Wi-Fi,” Proceedings of Engineering and Technology Innovation, vol. 16, pp. 1-12, August 2020.

[4] K. A. Khan and S. M. Nokerov, "Optimization of Multi-Band Characteristics in Fan-Stub Shaped Patch Antenna for LTE(CBRS) and WLAN Bands,” Proceedings of Engineering and Technology Innovation, vol. 18, pp. 25-35, April 2021.

[5] P. Li, J. Liang, and X. Chen, "Study of Printed Elliptical/Circular Slot Antennas for Ultrawideband Applications," IEEE Transactions on Antennas and Propagation, vol. 54, no. 6, pp. 1670-1675, June 2006. 
[6] A. J. A. Al-Gburi, I. M. Ibrahim, M. Abdulhameed, Z. Zakaria, M. Zeain, H. H. Keriee, et al., "A Compact UWB FSS Single Layer with Stopband Properties for Shielding Applications,” Przegląd Elektrotechniczny, vol. 2, pp.165-168, February 2021.

[7] P. P. Shome, T. Khan, and R. H. Laskar, "A State-of-Art Review on Band-Notch Characteristics in UWB Antennas," International Journal of RF and Microwave Computer-Aided Engineering, vol. 29, no. 2, e21518, February 2019.

[8] Y. L. Zhao, Y. C. Jiao, G. Zhao, L. Zhang, Y. Song, and Z. B. Wong, "Compact Planar Monopole UWB Antenna with Band-Notched Characteristic," Microwave and Optical Technology Letters, vol. 50, no. 10, pp. 2656-2658, October 2008.

[9] Y. D. Dong, W. Hong, Z. Q. Kuai, and J. X. Chen, “Analysis of Planar Ultrawideband Antennas with On-Ground Slot Band-Notched Structures,” IEEE Transactions on Antennas and Propagation, vol. 57, no. 7, pp. 1886-1893, July 2009.

[10] Z. A. Zheng, Q. X. Chu, and Z. H. Tu, "Compact Band-Rejected Ultra-Wideband Slot Antennas Inserting with $\lambda / 2$ and $\lambda / 4$ Resonators," IEEE Transactions on Antennas and Propagatation, vol. 59, no. 2, pp. 390-397, February 2011.

[11] D. H. Lee, H. Y. Yang, and Y. K. Cho, "Tapered Slot Antenna with Band-Notched Function for Ultrawideband Radios," IEEE Antennas and Wireless Propagation Letters, vol. 11, pp. 682-685, June 2012.

[12] K. H. Kim and S. O. Park, "Analysis of the Small Band-Rejected Antenna with the Parasitic Strip for UWB," IEEE Transactions on Antennas and Propagation, vol. 54, no. 6, pp. 1688-1692, June 2006.

[13] A. M. Abbosh and M. E. Bialkowski, "Design of UWB Planar Band-Notched Antenna Using Parasitic Elements," IEEE Transactions on Antennas and Propagation, vol. 57, no. 3, pp. 796-799, March 2009.

[14] D. Yadav, M. P. Abegaonkar, S. K. Koul, V. Tiwari, and D. Bhatnagar, "A Compact Dual Band-Notched UWB Circular Monopole Antenna with Parasitic Resonators,” AEÜ-International Journal of Electronics and Communications, vol. 84, pp. 313-320, February 2018.

[15] Y. D. Dong, W. Hong, Z. Q. Kuai, C. Yu, Y. Zhang, J. Y. Zhou, et al., "Development of Ultrawideband Antenna with Multiple Band-Notched Characteristics Using Half Mode Substrate Integrated Waveguide Cavity Technology," IEEE Transactions on Antennas and Propagation, vol. 56, no. 9, pp. 2894-2902, September 2008.

[16] M. Yazdi and N. Komjani, "Design of a Band-Notched UWB Monopole Antenna by Means of an EBG Structure," IEEE Antennas and Wireless Propagation Letters, vol. 10, pp. 170-173, February 2011.

[17] N. Jaglan, S. D. Gupta, B. K. Kanaujia, and S. Srivastava, "Band Notched UWB Circular Monopole Antenna with Inductance Enhanced Modified Mushroom EBG Structures,” Wireless Networks, vol. 24, no. 2, pp. 383-393, February 2018.

[18] L. Peng and C. L. Ruan, "UWB Band-Notched Monopole Antenna Design Using Electromagnetic-Bandgap Structures," IEEE Transactions on Microwave Theory and Techniques, vol. 59, no. 4, pp. 1074-1081, April 2011.

[19] K. A. Alshamaileh, M. J. Almalkawi, and V. K. Devabhaktuni, "Dual Band-Notched Microstrip-Fed Vivaldi Antenna Utilizing Compact EBG Structures,” International Journal of Antennas and Propagation, vol. 2015, pp. 1-7, February 2015.

[20] N. Jaglan, B. K. Kanaujia, S. D. Gupta, and S. Srivastava, "Dual-Band Notched EBG Structure Based UWB MIMO/Diversity Antenna with Reduced Wide Band Electromagnetic Coupling,” Frequenz, vol. 71, pp. 555-565, October 2017.

[21] N. Jaglan, B. K. Kanaujia, S. D. Gupta, and S. Srivastava, "Design of Band Notched Antenna with DG-CEBG," International Journal of Electronics, vol. 105, no. 1, pp. 58-72, January 2018.

[22] N. Jaglan, B. K. Kanaujia, S. D. Gupta, and S. Srivastava, "Triple Band Notched UWB Antenna Design Using Electromagnetic Band Gap Structures,” Progress in Electromagnetics Research C, vol. 66, pp. 139-147, July 2016.

[23] T. Li, H. Q. Zhai, G. H. Li, and C. H. Liang, "Design of Compact UWB Band-Notched Antenna by Means of Electromagnetic-Bandgap Structures,” Electronics Letters, vol. 48, no. 11, pp. 608-609, May 2012.

[24] N. Jaglan, S. D. Gupta, and S. Srivastava, "Notched UWB Circular Monopole Antenna Design Using Uni-Planar EBG Structures," International Journal on Communications Antenna and Propagation, vol. 6, no. 5, pp. 266-273, October 2016.

[25] S. Peddakrishna and T. Khan, "Design of UWB Monopole Antenna with Dual Notched Band Characteristics by Using $\pi$-Shaped Slot and EBG Resonator," AEÜ-International Journal of Electronics and Communications, vol. 96, pp. 107-112, November 2018.

[26] S. Modak, T. Khan, and R. H. Laskar, "Loaded UWB Monopole Antenna for Quad Band-Notched Characteristics," IETE Technical Review, in press.

[27] M. K. Abdulameed, M. S. B. M. Isa, Z. Zakaria, I. M. Ibrahim, M. K. Mohsen, M. L. Attiah, et al., "Radiation Control of Microstrip Patch Antenna by Using Electromagnetic Band Gap,” AEÜ-International Journal of Electronics and Communications, vol. 110, 152835, October 2019.

[28] S. Peddakrishna, T. Khan, S. K. K. Dash, and S. Kumar, "Design and Experimental Characterization of Novel Compact Planar EBG Structure,” IEEE Applied Electromagnetics Conference, December 2017, pp. 1-2.

[29] M. K. Abdulameed, M. S. B. M. Isa, Z. Zakaria, I. M. Ibrahim, M. K. Mohsen, M. L. Attiah, et al., "Enhanced Performance of Compact $2 \times 2$ Antenna Array with Electromagnetic Band-Gap,” Microwave and Optical Technology Letters, vol. 62, no. 2, pp. 875-886, February 2020. 